\title{
PHP Frameworks Usability in Web Application Development
}

\author{
Norhaidah A. Haris, Nurdatillah Hasim
}

\begin{abstract}
A framework defined as a structure that supports the development of dynamic websites, web applications, and services. Framework code and design are often reusable to assist customization, resource service, and API-related tasks. This study discussed current practice to help a developer understand PHP frameworks adoption for web application development. Three approaches were selected to understand the features suitability of the PHP frameworks: the systematic approach, score criteria evaluation, and PHP framework technical factors. A comparison of 23 different frameworks features also has been studied that involves features such as ORM, Code Generator, Template Engine, and CRUD Generator. Besides PHP framework features, understanding the basic core PHP to build web application would help a lot in learning PHP frameworks. Moreover, new developers should not limit themselves to a particular PHP framework only but also allow themselves to explore various PHP frameworks in the development of web application projects.
\end{abstract}

Index Terms: PHP framework, Web Application, User Experience, Usability

\section{INTRODUCTION}

PHP was initially developed by Rasmus Lerdoff in 1994 to watch over his online resume and related personal information in which PHP initially named as" Personal Home Page". However, two programmers Zeev Suraski and Andi Gutmans rebuilt, updated and released the PHP core in 1997 and changed the acronym PHP to" Hypertext Processor" [9]. Through time PHP has evolved and PHP has been used as a language for the World Wide Web (WWW) or so called Internet in which developers find PHP is a language that easy to learn, community friendly, freely available as an open source software and easily to deployed. The current PHP environment requires developers to create interfaces components of the system, link to database and user authentication. The usage of framework could overcome the problems during development life cycle environment by reuse of code which could save times and costs to design, developing codes and tests [13]. This study discussed on the current practice to understand PHP language and PHP frameworks in building web application. Any developer who wished to adopt the PHP framework to build web applications should understand on the basic concept related to PHP framework and grab the necessary knowledge and skill required to become a competent web application developer.

The significance of this study will provide an insight for developers who wished to develop web application using PHP frameworks. Developers would have better knowledge on which PHP frameworks that are suitable to be implemented in their web application development environment.

\section{RELATED STUDIES ON PHP FRAMEWORKS}

PHP is a server-side programming language which commonly used for websites development. The studies conducted by W3Techs [2] has identified that PHP is the most popular server-side programming languages for websites development as shown in Figure 1 [2].

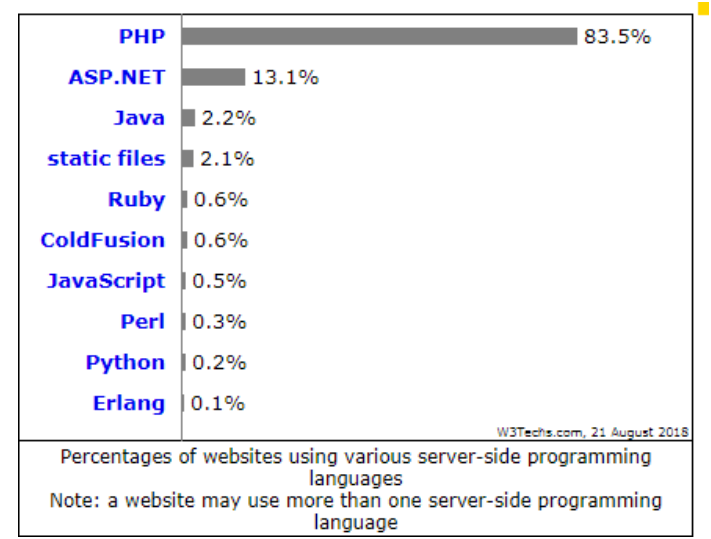

Figure 1: Server-side programming languages for websites development

PHP or core PHP is a basic programming language which could also be used to develop dynamic web pages. The core PHP works without libraries or built-in functionalities and usually developers have to make the code script using their skills and logic. On the other hand, PHP framework is a framework that consist a collection of organized source codes in a specified architecture to support the development of dynamic websites applications and services [26]. 
There are a few comparison studies have been conducted by researchers to identify which of PHP frameworks would provide developers with better features regarding performance, development process and code maintenance. These researchers have conducted several testing such as load testing and stress testing to measure the performance efficiency on the specified PHP frameworks. The discussion involved the suitability choices on various issues related to PHP frameworks for specified web application development. Usually, the comparison made based on the researchers' interest to study in depth on certain PHP frameworks. A few PHP frameworks comparison studies which have been conducted are as follows:

1) CakePHP and CodeIgniter [10], [7].

2) CakePHP, Yii, Zend, CodeIgniter, Prado and Symfony [26].

3) CodeIgniter, Laravel and core PHP [6].

4) Symfony, laravel, CodeIgniter, Phalcon and core PHP [24].

5) CakePHP, Laravel and CodeIgniter [15].

6) CakePHP2, CodeIgniter, Symfony2, Yii and Phalcon [23].

7) CakePHP, CodeIgniter, Laravel, Symphony, Yii and Zend Framework [17].

Most of these studies have chosen either CakePHP or Code Igniter or both in comparing with other PHP frameworks such as Yii, Zend, Prado, Symfony, Laravel and Phalcon. CakePHP and CodeIgniter have been used for quite some time since their release in 2005 and 2006 respectively compared with other frameworks which are released a few years ago. These studies also suggest developers who wished to learn PHP frameworks should have first knowledge of the PHP language itself. Besides, they might as well learned HTML, CSS, JavaScript and MySQL to have a firm understanding of the fundamental development of web application.

Understanding frameworks require techniques in governing modern software development. The PHP developers would have exposure in developing appealing application, clear view on the use of design patterns, illustrate the concepts on more complex GUI frameworks, understanding the collaboration pattern especially the reuse of design and code, exposure on the commercial tools, utilization of the OOP concepts [4] and understand the MVC frameworks concepts in displaying powerful and flexible software design [28]. However, to choose which PHP frameworks most suitable and easy to learn in the shortest time requires careful studies.

Recently, the most popular PHP frameworks in 2018 as discussed in a survey by Lunarpages are Laravel, CodeIgniter, Symfony, Phalcon and CakePHP [16]. However, even though Laravel is the most popular but for beginners strong understanding of core PHP and OOP concepts such as classes, objects, properties, methods and other framework features is essential.

\section{PHP FRAMEWORKS CONCEPT}

A framework is defined as the skeleton for an application with a built in collection of related objects, factored into classes in which the framework code or design are reusable [8]. In other words, a framework is a collection of source codes organized into an architecture that supports the development of dynamic websites, web applications and services [26]. Frameworks also assist for customization, resource service and API-related tasks [21].

1) The concept of a PHP framework is related to Object Oriented Programming (OOP) and Model View Controller (MVC). MVC is a design pattern that applies the concept of software development and originally designed to provide multiple views of the same data virtually for modern inter- active applications [18]. The MVC pattern allows the interaction of data and methods in multiple classes and offers possible solutions to problems which could arise in the application development [4]. MVC pattern has three separate application components as follows [26]: Model —represent data structure relationship and dependencies which provides an interface to manipulate all classes corresponding to the logical object of the application.

2) View - represent screen presentation on different de- vices in which the application could have multiple views of the data.

3) Controller -represent as an information collector or input for the user and transfers the information to the model.

The idea of having MVC in PHP frameworks are the code presentation and layout will be simpler and well separated that will make the application more maintainable. In other words, the controller could easily handle the view inside the files and the logic inside the model [1]. Figure 2 shows the interaction flows between each component in MVC pattern [20]. Basically, MVC would improves the PHP process flow by effectively divided the flow into smaller steps and separate them clearly. The motivations in using MVC are as follows [20]:

1) Built in libraries, helpers and less codes to developed application functionality.

2) Standardize, consistency and predictability and allow software components to be shared and reused.

3) Allows easy visualization on how the entire system works.

4) Security, interoperability and maintenance. Besides MVC pattern the

OOP concept is also implemented in PHP frameworks. OOP is a

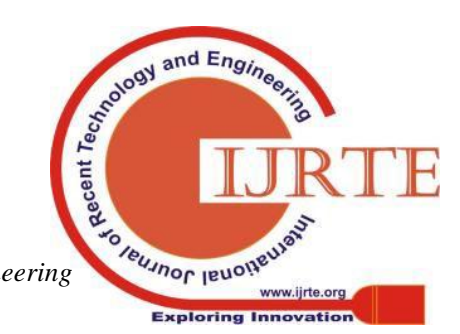


programming languages concept which abstract the data, logic and interactions into a set of objects. The areas of Object Oriented (OO) involves the concept such as class, instance, method, message passing, inheritance, abstraction, encapsulation, polymorphism and decoupling [5]. However, this study will not discuss further on the OOP concepts.

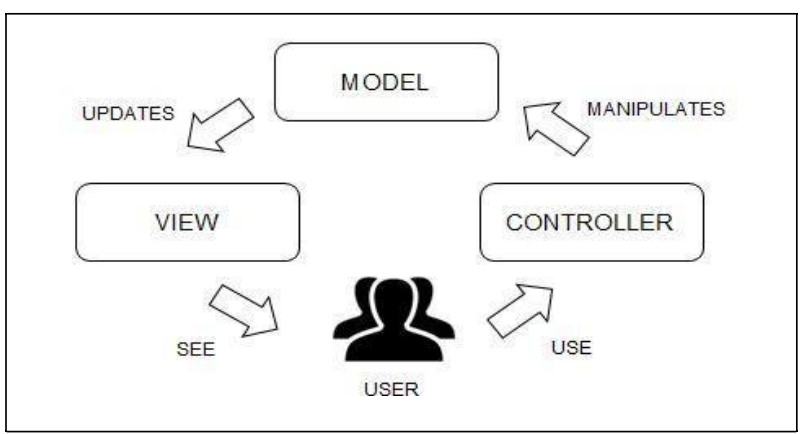

\section{THE SELECTION OF PHP FRAMEWORKS APPROACH}

Any developers who have the intention to build knowledge and skill regarding PHP frameworks requires to be vigilant on the current trend regarding the development on web application technologies. Currently, there are many PHP frameworks with unique features, thus careful selection should be made to identify which framework is suitable for them. The question aroused how to choose the right PHP frameworks because the choice might depend on which PHP frameworks that have a large user base and community support, useful features, popular, trendy and widely used [4].

This study has identified that there are three approaches could be conducted to identify on the choice on which PHP frameworks should be selected for beginners or anybody who wished to fully understand the concept of PHP frameworks at the initial stage. The approach is a Systematic approach, Score Criteria Evaluation, and PHP framework technical factors.

\section{A. Systematic Approach}

The systematic approach proposed by Parker [22] described the commonly approach used in selecting software tools for the IT curriculum. This study adopted the systematic approach on the selection of the suitable PHP frameworks as follows:

1) Compile the PHP frameworks criteria list.

2) Weight each of the criteria of the PHP frameworks.

3) Determine the PHP frameworks list.

4) Rate each of the PHP frameworks.

5) Calculate the weighted score for every PHP framework.

The systematic approach requires each of the PHP frameworks to be tested using a few evaluation criteria such as performance, maintenance, suitability, and other software assessment evaluation. Hence, the relevance of the PHP frameworks could be determined through the weight score of each PHP frameworks that have been tested. Another study conducted by Milos and Zurkiewicz [17] suggested that evaluation on PHP frameworks weightage criteria should include these analyses as follows:

1) Documentation and technical support - to ensure the source code reliability.

2) Tools are supporting web application development - to reduce programmer's workload with generated source codes.

3) Programming techniques - to reduce the amount of source code for a reliable application.

4) Database technologies - to allow applications to integrate with other elements of the system.

5) Caching (Buffering)- to ensure optimum performance application.

6) Integration - to ensure compatibility with other elements of IT system.

7) Conciseness of source code-to reduce the possibility of making mistakes in improving the reliability of the application.

8) Framework efficiency-important to determine the server workload so the resources could be used intensively.

Therefore, any organization who wished to adopt any PHP frameworks for building their IT system or application should consider the weight criteria as proposed.

\section{B. Score Criteria Evaluation}

Another assessment approach is using score criteria evaluation. The score criteria evaluation is adopted from Chao et al. [4] to identify which PHP framework is relevant to be learned or taught for beginners. Chao studies has makes a few comparison of the PHP frameworks such as Zend, CakePHP, CodeIgniter, Yii, and Symfony.

Chao et al. suggested any organization especially Higher Education Institution(HEI) which have planned to adopt PHP frameworks in preparing their students with PHP skills and knowledge should consider these evaluative scores criteria as follows: -

1) Pedagogical features-students learning curve associated with framework complexity for beginners [12] and ample time to study in at least four months or a semester for in-depth understanding [22].

2) Industry penetration - students have marketable skills and the adoption of industry software tools and technologies will expose students with future workplace practices [14].

3) Support and Training requirement - resources on various aspects such as availability of documentation, training and support for both Instructors and students [3].

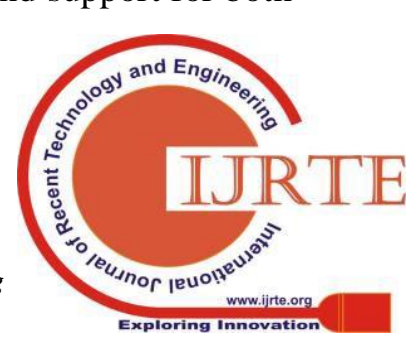


4) Software Cost-PHP frameworks usually are open source software.

5) Software Characteristics-Most PHP frameworks have similar features and are available on all platforms.

6) Course Methodology / Software Paradigm-PHP frameworks usually implement an MVC design pattern.

7) Acceptance in Academic Environment-perception about PHP frameworks suitability in IT curriculum.

Chao et al study discussed that pedagogical features are the most important in choosing the right PHP frameworks. The weighted score for each criteria elements of the result also suggested that the Yii PHP framework has the highest ratings compared to CodeIgniter, Cake PHP, Symfony, and Zend [4]. However, in another study conducted by Prokofyeva and Boltunova,, the CakePHP is identified as the easiest PHP framework to learn compared to Zend which is quite complex, CodeIgniter and Symfony are moderately easy and complex[23].

Therefore, selecting the most appropriate framework for beginners or students in HEI usually requires the academician involves in the course planning should do extensive research and well versed hands-on experience [4].

\section{PHP Framework Technical Factors}

Apart from understanding the criteria in learning PHP, the PHP framework technical factors which are related to the PHP framework components suitability [29] are essential to be studied such as the performance of the framework related to the source code, the framework documentation quality and availability of technical support. Other technologies feature that already built in the PHP frameworks are application tools, support technologies and programming technique should also be considered as listed follows:

a)

Web Application Tools: The frameworks usually distributed together with tools that support the development of the source code elements. The tools could speed up the process of developing the source code of an application, reduce programmer's workload and decrease programming mistake [29]. The tools that support the MVC patterns should have the following elements:

1) Models - MVC pattern represent a problem subject to business logic in which models is use for table mapping.

2) CRUD - (Create, Read, Update and Deletæ) records) tools enable to perform basic operations on the database record.

3) Controller — classes are responsible for the functionality of a controller in MVC pattern.

4) Views - MVC pattern elements.

5) Forms - single classes or groups of classes responsible for rendering and validating logic of entry data.

6) Modules - separate functionality and ensure the portability of the source code between projects.

b) Support Technologies and Programming Technique: The support technologies and programming techniques vary based on the framework usefulness for the development of web application project as follows [29], [17]:

1) Model-View-Controller (MVC).

2) Object Relational Mapping (ORM) - technique for mapping database objects and relationship between programming language classes.

3) Code generator - generate resources like views, controllers, routes, migrations and form requests.

4) DB objects - support access to databases.

5) Templates - support techniques in managing templates (two step view or composite view).

6) Cache - technique for storing intermediate results.

7) AJAX - frameworks provide classes that increase performance and simplify source code.

8) Modules - divide source code into functionality groups which improves management and portability of source code between projects.

9) EDP (Event Driven Programming) - source code organization technique.

10)Namespace - provide better source code management.

Consequently, the PHP frameworks technologies are to simplify the complexity of the development of web applications. Currently, there are 42 different type of PHP frameworks for web application development [11]. However, this study only compare 21 PHP frameworks features as shown in Table 1. Other framework such as Flight, Meedo, Simple MVC, PHP Mini, Silex (reached its end of life in June 2018), Typo 3 Flow, Guzzle PHP, YAF, Akelos PHP, Qcodo, evoCore, Stratus, Seagul, Maintainable, Limb, Phocoa, AjaxAc, Zoop, BlueShoes, Recess and PHPDevShell that are not listed in Table 1 will not be discussed deeply in this paper because the insufficient information regarding the frameworks. The features that should be considered in the selection of PHP frameworks are ORM, Code Generator, Template Engine and CRUD Generator.

Template engine in a framework is useful in separating between application logic and display logic, therefore the back-end developers and front-end developers could collaborate on the same areas of the website and they will not interfere with each other codes. The common template engines are Blade, Mustache, Smarty, Twig and Volt.

c) PHP Micro-framework: The micro-frameworks are designed specifically to simplify development of small websites. They usually do not have some of the advanced features provided by other frameworks listed in Table 1. The fewer features and modules make it lightweight and fast. Therefore, integration between the micro-framework and small website will not be affecting its performance and user experience. Each micro-framework offers features to up development of small web application, while reducing 
overheads and simplifying deployment. Listed are the PHP micro-frameworks.

1) Laravel - laravel.com

2) Symfony - symfony.com

3) CodeIgniter - codeigniter.com

4) Yii Framework - yiiframework.com

5) Phalcon - phalcon.com

6) PHPixie - phpixie.com

7) Slim - slimframework.com

8) POP PHP - popphp.org

9) Fat-free - fatfreeframework.com

10) Limonade - limonade-php.github.io

\section{DISCUSSION AND CONCLUSION}

The PHP framework requirement decision is also important to be put into consideration whether to use a framework or develop from scratch. There are a few requirements that vital to be considered in the development of web application using framework as shown in Table 2 on the advantages and disadvantages using frameworks [25].

Besides the advantages discussed in Table 2, PHP frameworks exploitation is adequate for a large and complex web application, however, for the small and simple web applications the benefits of frameworks could not be fully utilized, and justification should be made whether the framework usage is over sufficient and thorough consideration or evaluation is required [27]. On the other hand, the core PHP works without any extra library and developers involved should have strong programming skill and logic. Consequently, developers with a strong foundation of core PHP would find PHP frameworks are much easier to understand especially if the basic knowledge of the core PHP such as functions, classes, and methods is deeply well-versed.

Looking at this situation for developers who wished to start using frameworks, understanding core PHP to build web application would amazingly help to improves the web development as a whole and developers will not limit themselves to a particular PHP framework only [19]. The beginner developer should also consider learning the easiest framework as discussed by Chao et al [4] to build their knowledge and skills confidence level. Another important thing that should be considered is the framework selection criteria such as built-in feature actively developed or improved, continuous supported from service provider and follow the software engineering practices. Lastly, the conclusion is the choice of the PHP framework is dependent on the web application project in which every project has different requirement or features and sometimes the choice might not quite suitable for the next new project.

The PHP framework requirement decision is also important to be put into consideration whether to use a framework or develop from scratch. There are a few requirements that vital to be considered in the development of web application using framework as shown in Table 2 on the advantages and disadvantages using frameworks [25].

Besides the advantages discussed in Table 2, PHP frameworks exploitation is adequate for a large and complex web application, however, for the small and simple web applications the benefits of frameworks could not be fully utilized, and justification should be made whether the framework usage is over sufficient and thorough consideration or evaluation is required [27]. On the other hand, the core PHP works without any extra library and developers involved should have strong programming skill and logic. Consequently, developers with a strong foundation of core PHP would find PHP frameworks are much easier to understand especially if the basic knowledge of the core PHP such as functions, classes, and methods is deeply well-versed.

Therefore, developers who wished to start using frameworks are require to understand the core PHP to build web application. The knowledge would amazingly help to improves the web development as a whole and developers will not limit themselves to a particular PHP framework only [19]. The beginner developer should also consider learning the easiest framework as discussed by Chao et al [4] to build their knowledge and skills confidence level. Another important thing that should be considered is the framework selection criteria such as built-in feature actively developed or improved, continuous supported from service provider and follow the software engineering practices. Lastly, the conclusion is the choice of the PHP framework is dependent on the web application project in which every project has different requirement or features and sometimes the choice might not quite suitable for the next new project.

\section{REFERENCES}

[1] M. Young, The Technical Writer's Handbook. Mill Valley, CA University Science, 1989. Principles of mvc for php developers. Available

https://www.htmlgoodies.com/beyond/php/article.php/391221 1/Principles-Of-MVC-for-PHP-Developers.htm. Accessed:22Aug-2018. 
[2] Usage of server-side programming languages for websites. Available at https://w3techs.com/ technologies/overview/programminglanguage/all Accessed:22-Aug-2018.

[3] C. Beise. Revisiting database resource choice: A framework for dbms course tool selection. AMCIS 2006 Proceedings, page 266, 2006.

[4] J. Chao, K. Parker, and B. Davey. Navigating the framework jungle for teaching web application development.

[5] In Proceedings of the Informing Science and Information Technology Education Conference. Informing Science Institute, 2013.

[6] S. Cook. Languages and object-oriented programming. Software Engineering Journal, 1(2):73-80, 1986.

[7] R. Das and L. P. Saikia. Comparison of procedural php with codeigniter and laravel framework. International Journal of Current Trends in Engineering \& Research,2(6):42-8,2016.

[8] A. R. Fayyaz and M. Munir. Performance evaluation of php frameworks (cakephp and codeigniter) in relation to the objectrelational mapping, with respect to load testing, 2014

[9] E. Gamma. Design patterns: elements of reusable object-oriented software. Pearson Education India, 1995.

[10] P. Group et al. History of php. Viitattu, 6:2011, 2011.

[11] A. K. Himawan. Performance analysis framework codeigniter and cakephp in website creation. International Joumal ofComputer Applications, 94(20), 2014.

[12] J. K. Top 42 php frameworks for modern web development, Jun 2018. Available at https://acodez.in/best-php-frameworks/ Acessed: 22-Aug-2018.

[13] D. Kao, W. Tousignant, and N. Wiebe. A paradigm for selecting an institutional software. In Proceedings ISECON, volume 17, page $207,2000$.

[14] J. Knupp. What is web framework, Mar 2014. Available at https://jeffknupp.com/blog/2014/03/03/ what-is-a-webframework/ Accessed:22-Aug-2018

[15] L. Lancor and S. Katha. Analyzing php frameworks for use in a project-based software engineering course. In Proceeding of the 44th ACM technical symposium on Computer science education, pages 519524. ACM, 2013

[16] X. Li, S. Karnan, and J. A. Chishti. An empirical study of three php frameworks. In Systems and Informatics (ICSAI), 2017 4th International Conference on, pages 1636-1640. IEEE, 2017.

[17] Lunarpages. Most Popular PHP Frameworks of 2018, July 11 2018. Available at http://lunarpages.com/ most-popular-php-frameworks-of-2018/. 22-Aug-2018.

[18] M. Mi losz and A. Zurkiewicz. Selecting a php framework for a web application project-the method and case study. 9th international technology. In Education and Development ConferenceINTED, pages 2-4, 2015.

[19] S. F. Morse and C. L. Anderson. Introducing application design and software engineering principles

[20] Nishtha. Core PHP Vs PHP Framework,Best Practices, Nov 29 2017. Available at http://nmgtechnologies.com/blog/corephp-vs-php-framework.html. Accessed: 22-aug-2018.

[21] R. F. Olanrewaju, T. Islam, and N. Ali. An empirical study of the evolution of php mvc framework. In Advanced Computer and Communication Engineering Technology, pages 399-410. Springer, 2015.

[22] S. Pandey. Development of a web application (idomain) in the codeigniter framework: Hosting accounts management system development. 2016.

[23] K. R. Parker. Selecting software tools for is/it curricula. Education and Information Technologies, 15(4):255-275, 2010.

[24] N. Prokofyeva and V. Boltunova. Analysis and practical application of php frameworks in development of web information systems. Procedia Computer Science, 104:51-56, 2017.

[25] J. Samra. Comparing performance of plain php and four of its popular frameworks, 2015.

[26] T. J. Shelford and G. A. Remillard. Real Web Project Management: Case Studies and Best Practices from the Trenches. Addison-Wesley Professional, 2003.

[27] M. Thanh Nguyen et al. Adopting web framework in webapplication development. 2008.

[28] I. P. Vuksanovic and B. Sudarevic. Use of web application frameworks in the development of small applications. In MIPRO, 2011 Proceedings of the 34th International Convention, pages 458-462. IEEE, 2011.

[29] M. R. Wick. Kaleidoscope: using design patterns in cs1. ACM SIGCSE Bulletin, 33(1):258-262,2001.

[30] M. Zurkiewicz and M. Milosz. Selecting a php framework for web application projects: the method and case study. no. April, 2015 .

\section{AUTHORS PROFILE}

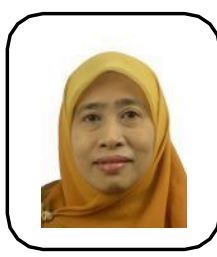

Prior working as a lecturer in November 2002, in Management Science University (MSU) and have been contributing her knowledge and experience in UniKL since 2005 in Software Engineering department. She also has a personal mission to educate an empower individuals with the necessary knowledge in order to achieve their personal and organizational goals. Research interests include Information Systems

(Decision Support System, Recommender System, and Management Information System), Artificial Intelligence, Machine Learning, Open Source Software and Software Engineering. Currently, active doing research in this areas.

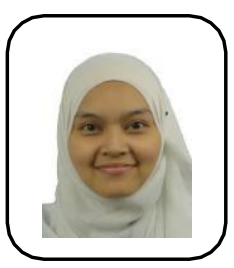

Nurdatillah Hasim received her Bachelor of Information Technology in Software Engineering from Universiti Malaysia Terengganu in 2007 and obtained her Master of Science in Real-Time Software Engineering from Universiti Teknologi Malaysia in 2009. Currently she is a lecturer at Malaysian Institute of Information Technology (MIIT), Universiti Kuala Lumpur under Software Engineering Section. Her research interests include software metrics and quality as well as software engineering in general. 
International Journal of Recent Technology and Engineering (IJRTE) ISSN: 2277-3878, Volume-8 Issue-3S, October 2019

\begin{tabular}{|c|c|c|c|c|c|c|c|}
\hline $\begin{array}{c}\text { Framework } \\
\text { Name }\end{array}$ & License & $\begin{array}{c}\text { PHP } \\
\text { Version }\end{array}$ & ORM & $\begin{array}{c}\text { Code } \\
\text { Generator }\end{array}$ & $\begin{array}{c}\text { Template } \\
\text { Engine }\end{array}$ & $\begin{array}{c}\text { CRUD } \\
\text { Generator }\end{array}$ & Website \\
\hline Laravel & MIT & $>=$ PHP 5.4 & Eloquent & Artisan CLI & Blade & $\begin{array}{l}\text { Laravel } \\
\text { Backpack } \\
\text { /CRUD }\end{array}$ & laravel.com \\
\hline Symfony & MIT & $\begin{array}{l}>=\text { PHP } \\
5.5 .9\end{array}$ & $\begin{array}{l}\text { Doctrine 2, } \\
\text { Propel }\end{array}$ & CLI & $\begin{array}{l}\text { PHP, } \\
\text { Twig }\end{array}$ & $\begin{array}{l}\text { Sensio } \\
\text { Generator } \\
\text { Bundle }\end{array}$ & symfony.com \\
\hline CodeIgneiter & MIT & $\begin{array}{ll}>= & \text { PHP } \\
5.1 .6 & \end{array}$ & $\begin{array}{l}\text { Doctrine, } \\
\text { Active } \\
\text { Record }\end{array}$ & & $\begin{array}{l}\text { PHP, } \\
\text { Twig }\end{array}$ & $\begin{array}{l}\text { Grocery } \\
\text { CRUD }\end{array}$ & codeigniter.com \\
\hline Yii & BSD & $>=$ PHP 5.4 & $\begin{array}{l}\text { Database } \\
\text { Access } \\
\text { Object } \\
\text { (DAO), } \\
\text { Active Record }\end{array}$ & $\begin{array}{l}\text { Yii, CLI, } \\
\text { Gii, } \\
\text { (Web based) }\end{array}$ & $\begin{array}{l}\text { Razor, } \\
\text { Smarty, } \\
\text { Twig }\end{array}$ & Gii & yiiframework.com \\
\hline Cake PHP & MIT & $\begin{array}{ll}>= & \text { PHP } \\
5.2 .8 & \end{array}$ & $\begin{array}{l}\text { Custom } \\
\text { (Cake PHP's } \\
\text { standard) }\end{array}$ & CLI & $\begin{array}{l}\text { Custom, } \\
\text { Smarty, } \\
\text { Twig }\end{array}$ & Scaffolding & cakephp.org \\
\hline Phalcon & BSD & & Phalcon & $\begin{array}{l}\text { Phalcon } \\
\text { Developer } \\
\text { Tools }\end{array}$ & Volt, PHP & Scaffolding & phalcon.com \\
\hline Zend & BSD & $>=$ PHP 5.3 & Doctrine & & & & zend.com \\
\hline Aura & & & $\begin{array}{l}\text { Aura Marsh } \\
\text { all }\end{array}$ & CLI & auraphp & ApiGen & auraphp.com \\
\hline Fuel PHP & MIT & & Doctrine & CLI & $\begin{array}{l}\text { Smarty, } \\
\text { Twig, Dwoo }\end{array}$ & $\begin{array}{l}\text { Model } \\
\text { CRUD, } \\
\text { Scaffolding }\end{array}$ & fuelphp.com \\
\hline PHPixie & BSD & $\begin{array}{l}>=\text { PHP } \\
5.3 .0\end{array}$ & PHPixie & & & & phpixie.com \\
\hline Kohana & BSD & $>=$ PHP 5.0 & Custom & & Twig & & kohanaframework.org \\
\hline $\begin{array}{l}\text { Slim } \\
\text { Ver. } 3.11\end{array}$ & & $>=$ PHP 5.5 & $\begin{array}{l}\text { Doctrine, } \\
\text { Eloquent }\end{array}$ & Yeoman & $\begin{array}{l}\text { Twig, } \\
\text { Smarty }\end{array}$ & $\begin{array}{l}\text { Slim } \\
\text { Framework } \\
3 \text { skeleton }\end{array}$ & slimframework.com \\
\hline Fat-Free & GNU & N/A & $\begin{array}{l}\text { Axon(SQL), } \\
\text { M2 } \\
\text { (Mango DB), } \\
\text { Jig(Flatfiles) }\end{array}$ & CLI & $\begin{array}{l}\text { PHP, } \\
\text { custom } \\
\text { plugin, } \\
\text { Twig, } \\
\text { Haanga, } \\
\text { Smarty }\end{array}$ & & fatfreeframework.com \\
\hline Nette & BSD & & Doctrine & & Latte, Twig & $\begin{array}{l}\text { Nette } \\
\text { CRUD }\end{array}$ & nette.org \\
\hline POP PHP & BSD & $>=$ PHP 5.6 & & CLI & & SQLite & popphp.org \\
\hline Zikula & GNU & $\begin{array}{l}>=\text { PHP } \\
5.4 .1\end{array}$ & Doctrine & $\begin{array}{l}\text { Module } \\
\text { Studio }\end{array}$ & Smarty & & zikula.org \\
\hline Prado & BSD & $>=$ PHP 5.3 & $\begin{array}{l}\text { Database } \\
\text { Access } \\
\text { Object } \\
\text { (DAO) }\end{array}$ & CLI & & & pradoframework.org \\
\hline Agavi & LGPL & & NO ORM & & Dwoo & & agavi.org \\
\hline Cappucino & GNU & $>=$ PHP 5.3 & & Objective $\mathbf{J}$ & & & $\begin{array}{l}\text { cappucino- } \\
\text { project.org }\end{array}$ \\
\hline Limonade & MIT & $\begin{array}{l}>=\text { PHP } \\
5.1 .6\end{array}$ & Eloquent & & Twig & & $\begin{array}{l}\text { lemonade-php. } \\
\text { github.io }\end{array}$ \\
\hline Webasyst & LGPL & $>=$ PHP 5.2 & & & Smarty & & webasyst.com \\
\hline
\end{tabular}

Table 1: PHP Frameworks Comparison 


\begin{tabular}{|l|l|l|}
\hline No & Advantages & Disadvantages \\
\hline 1 & $\begin{array}{l}\text { Complete environment for website } \\
\text { development, interoperability, security, and } \\
\text { maintenance. }\end{array}$ & $\begin{array}{l}\text { Complexity on framework code for certain } \\
\text { condition } \\
\text { which affects the performance and put burden } \\
\text { on the hardware. }\end{array}$ \\
\hline 2 & Standards, consistency and predictability. & $\begin{array}{l}\text { Security in the framework could affects the built } \\
\text { web application. }\end{array}$ \\
\hline 3 & Standard architecture for easy visualization & Require high learning curve \\
\hline 4 & $\begin{array}{l}\text { Able to share or reuse the codes in libraries, } \\
\text { classes and functions }\end{array}$ & $\begin{array}{l}\text { Strict framework convention that hinder } \\
\text { application flexibility and developer's creativity }\end{array}$ \\
\hline
\end{tabular}

Table 2: PHP Frameworks: Advantages and Disadvantages 